\title{
Ortner's Syndrome as First Clinical Presentation of Severe Pulmonar Arterial Hypertension
}

\author{
Bolaki $\mathbf{M}^{1}$, Fanaridis $\mathbf{M}^{1 *}$, Pediaditis $\mathrm{E}^{2}$, Mitrouska $\mathbf{I}^{1}$ and Georgopoulos $\mathrm{D}^{1,2}$
}

${ }^{1}$ Department of Pulmonary Medicine, University Hospital of Heraklion, University of Crete, Medical School, Heraklion, Crete, Greece

${ }^{2}$ Department of Intensive Care Medicine, University Hospital of Heraklion, University of Crete, Medical School, Heraklion, Crete, Greece

\begin{abstract}
A 40 year old female, non-smoker with a past medical history of urticaria and allergic rhinitis presented with hoarseness of voice of 3 months duration without any accompanying symptoms or limitation of daily activities. Direct laryngoscopy identified palsy of the left vocal cord. The magnetic resonance imaging of the chest indicated abnormal signal intensity in the left vocal cord. The thoracic computed tomography revealed only an enlargement of the pulmonary artery, while transthoracic echocardiography estimated systolic pulmonary artery pressure of 75 $\mathrm{mmHg}$. Pulmonary function tests were compatible with pulmonary vascular disease and cardiopulmonary exercise test showed exercise limitation of cardiocirculatory origin (maximum $\mathrm{O}_{2}$ consumption $60 \%$ of pred.). Catheterization of the right heart showed precapillary pulmonary hypertension (mean pulmonary artery pressure $40 \mathrm{mmHg}$ ) with a positive response to vasoreactivity test. A diagnosis of idiopathic pulmonary arterial hypertension (IPAH) was made, with hoarseness of voice as the only manifestation of the disease. The hoarseness of voice is believed to be the result of the compression of the left recurrent laryngeal nerve between aorta and the dilated pulmonary artery. This is an unusual case of cardiovocal syndrome (or Ortner's syndrome) in a patient with IPH who had no perception of dyspnea or limitation of daily activities.
\end{abstract}

Keywords: Hoarseness; Idiopathic pulmonary arterial hypertension; Cardiovocal syndrome; Catheterization of the right heart; Ortner's syndrome

\section{Case Report}

A 40 year old woman, non-smoker, was admitted to the hospital for evaluation of hoarseness of voice. The patient denied any accompanying symptom or limitation of her daily activities. Her past medical history included urticaria, allergic rhinitis and anxiety disorder. The only medication she received consisted of escitalopram $20 \mathrm{mg}$ (escitalopramSSRI). The patient a few days ago visited an otorhinolaryngologist complaining of persistence of hoarseness of voice for several months duration. Fiber-optic laryngoscopy revealed palsy of the left vocal cord and a thorough investigation began in order to identify the cause of the palsy. The magnetic resonance imaging of the neck showed shift of the left vocal cord towards the midline and abnormal signal intensity. The ultrasound of the thyroid gland and the computed tomography of the brain were normal. The computed tomography of the chest (CT) revealed: a) an increased diameter of the main pulmonary artery (3.7 $\mathrm{cm}), \mathrm{b}$ ) subtle effusion in the inferior part of the anterior pericardial petal and c) two micronodules in the periphery of the right lower lobe. On hospital admission the vital signs and oxygen saturation were normal (Figure 1). On heart auscultation the pulmonary component of the second heart sound was accentuated. The rest of clinical examination was unremarkable. The ECG revealed sinus rhythm, 75 $\mathrm{bpm}$, and incomplete RBBB and right axis deviation. The chest X-ray was considered as normal. Laboratory tests were within normal range, apart from a slightly increased erythrocyte sedimentation rate (17 $\mathrm{mm} / 1^{\text {st }}$ hour$)$ and mild lymphopenia $(1000 \mathrm{k} / \mu \lambda)$.

The clinical examination and CT findings were consistent with pulmonary hypertension and an extensive work up was performed. The echocardiography demonstrated severe enlargement of the right ventricle, a right to left movement of the intraventricular septum during systole ( $\mathrm{D}$-shaped left ventricle), severe tricuspid valve regurgitation (estimated systolic pulmonary artery pressure $75 \mathrm{mmHg}$ ) and a small pericardial effusion in the anterior part of the right ventricle. The findings of pulmonary function tests (PFTs) were compatible with pulmonary hypertension (decreased diffusion capacity for $\mathrm{CO}$

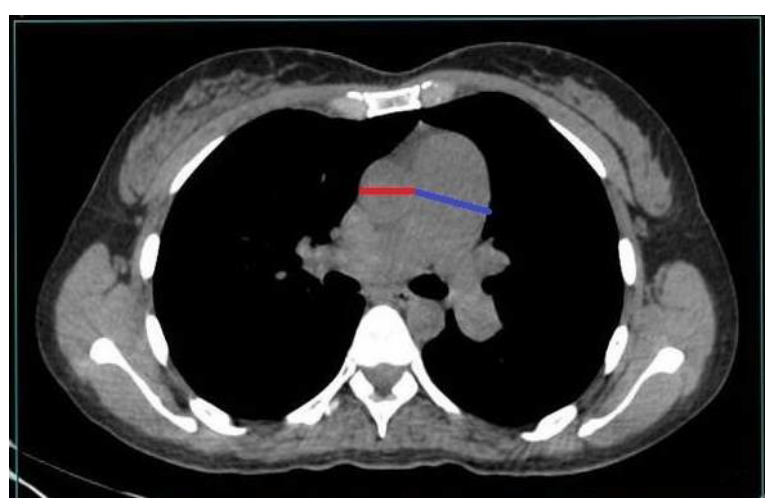

Figure 1: Chest CT showing dilatation of the pulmonary artery $(3.7 \mathrm{~cm}$ blue line).

with preserved alveolar volume). Furthermore, variable extrathoracic upper airway obstruction was evident in the maximum flow-volume loop, due to vocal cord paralysis. Cardiopulmonary exercise test (CPET) revealed a decrease in the maximum oxygen consumption (62\% pred.), attributed to a reduced maximum oxygen pulse which achieved an early plateau associated with a rapid increase in the heart rate to a predicted maximum value. The right heart catheterization confirmed the presence of precapillary pulmonary hypertension. The mean pulmonary artery pressure was $40 \mathrm{mmHg}$ with normal values

*Corresponding authors: Michail Fanaridis, Department of Pulmonary Medicine, University Hospital of Heraklion, University of Crete, Medical School, P.O. box 1352, Heraklion,711010, Crete, Greece, Tel: 2810392433; Fax: 2810542650; E-mail: michfana@gmail.com

Received November 30, 2016; Accepted January 17, 2016; Published January 21, 2016

Citation: Bolaki M, Fanaridis M, Pediaditis E, Mitrouska I, Georgopoulos D (2017) Ortner's Syndrome as First Clinical Presentation of Severe Pulmonar Arteria Hypertension. J Pulm Respir Med 6: 387. doi: 10.4172/2161-105X.1000387

Copyright: @ 2016 Bolaki M, et al. This is an open-access article distributed under the terms of the Creative Commons Attribution License, which permits unrestricted use, distribution, and reproduction in any medium, provided the original author and source are credited. 
of wedge (occlusion) pressure and cardiac output. The vasoreactivity test was positive. There was no evidence of connective tissue disorders. A diagnosis of idiopathic pulmonary arterial hypertension was made.

\section{Discussion}

To our knowledge this is the first case of idiopathic pulmonary arterial hypertension presenting with hoarseness of voice as a sole symptom and being investigated extensively with imaging tests, PFTS, CPET and right heart catheterization. Pulmonary arterial hypertension is an unusual cause of cardiovocal or Ortner's syndrome.

In general, hoarseness may be due to a variety of clinical conditions including inflammatory or irritant causes, neoplasia, neuromuscular and systemic diseases and psychiatric disorders [1]. Ortner [2] described a series of 3 cases of mitral stenosis suffering from hoarseness of voice because of left recurrent laryngeal nerve (RLN) palsy. Recurrent laryngeal nerve is a terminal branch of the vagus nerve that innervates the larynx with a different course on each side. The right RLN crosses the first part of the subclavian artery and hooks around to travel between the trachea and esophagus. The left RLN arises from the left vagal trunk in the thorax then crosses the arch of the aorta and hooks around the ligament arteriosum. Finally, ascends in the groove between the trachea and esophagus. The left RLN palsy is more common than the right RLN palsy. Ortner had initially suggested that the cause of the palsy was the enlargement of the left atrium pushing up the left RLN and compressing against the aortic arch. Nevertheless, it was later found that compression of the nerve between the aorta and pulmonary artery is responsible for the palsy [3]. The aorta has been shown to play an important role in the biomechanical environment of the RLN [4].

Although cardiovocal syndrome was initially described in the setting of mitral stenosis it has since been associated with a broader list [5] of cardiovascular pathology in adults including: atrial septal defect [6], patent ductus arteriosus [7], eisenmenger's syndrome [8], aortic aneurysm [9,10], primary pulmonary hypertension [11-13], mitral regurgitation [14] and congenital heart disease [15]. Chronic hoarseness is a rare symptom in infancy. Cardiovascular hoarseness was reported in 256 patients during the period 1980-2011 [16]. Hoarseness was the only symptom in $35 \%$ of patients and aortic aneurysms were the most common risk factors leading to hoarseness [16]. None of them had pulmonary arterial hypertension.

The patient started treatment with a calcium-channel blocker titrating according to systolic blood pressure (starting dose amlodipine $10 \mathrm{mg}$ but decreasing to $5 \mathrm{mg}$ ) Three months later the patient is being treated with amlodipine $15 \mathrm{mg}$ and does not report any other symptom or limitation of daily activities, while the hoarseness of voice was considerably improved. The patient status is followed regularly in the pulmonary hypertension clinic.

\section{Conclusion}

Though cardiovocal syndrome is rarely due to pulmonary arterial hypertension, on appropriate clinical grounds this disease should be suspected even if hoarseness of the voice is the only symptom.

\section{References}

1. Feierabend $\mathrm{RH}$, Shahram MN (2009) Hoarseness in adults. Am Fam Physician 80: 363-370.

2. Ortner N (1897) Recurrenslahmung bei mitral stenose. Wien Klin Wochenschr 10: 753-755.

3. Mulpuru SK, Vasavada BC, Punukollu GK, Patel AG (2008) Cardiovocal syndrome: a systematic review. Heart Lung Circ 17: 1-4.

4. Williams MJ, Ayylasomayajula A, Behkam R, Bierhals AJ, Jacobs ME, et al (2015) A computational study of the role of the aortic arch in idiopathic unilateral vocal-fold paralysis. J Appl Physiol 118: 465-474

5. Vahabzadeh-Hagh AM, Yim C, Fitter J, Chhetri DK (2015) Atrial Septal Defect and Left Recurrent Laryngeal Nerve Paralysis: A Case of Ortner's Syndrome and Literature Review. Int J Otolaryngol Head Neck Surg 4: 61-65.

6. Nee TS, Bin SA (2015) A rare cause of hoarseness-cardiovocal syndrome. Ann Otolaryngol Rhinol 2: 1068.

7. Nakao M, Sawayama T, Samukawa M, Mitake H, Nezuo S, et al. (1985) Left recurrent laryngeal nerve palsy associated with primary pulmonary hypertension and patent ductus arteriosus. J Am Coll Cardiol 5: 788-792.

8. Verbeke X, Vliebergh J, Sauer M, Leys M (2015) Hoarseness revealing Ortner's syndrome. Acta Clin Belg 70: 230.

9. Pathirana U, Kularatne S, Handagala S, Ranasinghe G, Samarasinghe R (2015) Ortner's syndrome presenting as thoracic aortic aneurysm mimicking thoracic malignancy: a case report. J Med Case Rep 9: 147.

10. Alves Zangirolami AC, Vieira de Oliveira F, Soares TM (2015) Ortner's sydrome: Secondary laryngeal paralysis caused by a great thoracic aorta aneurysm. Int Arch Otorhinolaryngol 19: 180-182.

11. Shah KD, Ayyer KH, Shah UK (1980) Hoarceness of Voice-A presenting manifestation of primary pulmonary hypertension. Indian J Otolaryngol 32: 35.

12. Rajasekhar $P$, Ramarao $P$, Bingi $P, P a n i ~ C ~(2014)$ A rare case of primary pulmonary hypertension with cardiovocal syndrome. Indian J Appl Res 4: 407-409.

13. Wilmshurst PT, Webb-peploe MM, Corker RJ (1983) Left recurrent laryngeal nerve palsy associated with primary pulmonary hypertension and recurrent pulmonary embolism. Br Heart J 49: 141-143.

14. Kumar Das S, Ghosh I, Das A, Kumar Dey S (2012) Mitral regurgitation: A rare cause of Ortner's syndrome. J Clin Diagn Res 6: 99-100.

15. Condon LM, Katkov H, Singh A, Helseth HK (1985) Cardiovocal syndrome in infancy. Pediatrics 76: 22-25.

16. Yuan SM (2014) Ortner (Cardio-vocal) Syndrome: a collective review. Kuwait Medical Journal 46: 3-13. 